\title{
Five minute recordings of heart rate variability for population studies: repeatability and age-sex characteristics
}

\author{
R Sinnreich, J D Kark, Y Friedlander, D Sapoznikov, M H Luria
}

\begin{abstract}
Objective-To evaluate the stability of short recordings of heart rate variability (HRV) with time, and the association of HRV with age and sex.

Design-Five minute Holter recordings were made twice over a two month interval (tracking study). In addition, HRV was measured in a cross sectional study.

Setting-Residents of 11 Israeli kibbutzim were examined in their settlements. Subjects-32 men and 38 women (aged 31-67) participated in the tracking study and 294 (aged 35-65) were involved in the cross sectional study.

Main outcome measures-Time and frequency domain analyses on Holter recordings were undertaken in two breathing conditions: spontaneous and controlled breathing (15 respirations per minute). Regression was used to assess the relations of sex, age, heart rate, and logarithmically transformed HRV indices.

Results-HRV measures were highly consistent with time with correlations of $0.76-$ 0.80 for high frequency and total power. Geometric mean total power declined with age by $45 \%$ in men and $32 \%$ in women, and was lower by $24 \%$ among women than among men (all $p \leqslant 0.005$ ). Men had a $34 \%$ higher very low and low frequency power and a higher ratio of low to high frequency power $(p<0.001)$. Conversely, high frequency power in women represents a greater proportion of total power than in men.

Conclusion-Short recordings of HRV in a non-laboratory setting are stable over months and therefore characteristic of an individual. Strong age and sex effects were evident. HRV derived from short recordings can be informative in population based studies.

(Heart 1998;80:156-162)
\end{abstract}

Keywords: heart rate variability; parasympathetic activity; reliability; sex differences

Heart rate variability (HRV) measures can provide non-invasive information on the autonomic nervous system, including its vagal and sympathetic components. ${ }^{1-4}$ Interest in these measures has increased recently in light of predictive associations between reduced HRV and increased mortality after an acute myocardial infarction (MI), ${ }^{5-8}$ and between HRV and the incidence of coronary heart disease and mortality in a community based population. ${ }^{9} 10$ These associations were independent of the effect of conventional risk factors. ${ }^{9}{ }^{10}$ Most studies of HRV have used 24 hour Holter recorded electrocardiograms (ECGs). Such measurement is often not feasible for widescale epidemiological studies, and may be unnecessary. In men after an acute MI, HRV measures calculated from 2-15 minute segments were remarkably similar to those calculated over 24 hours, and provided predictive information similar in strength to the entire record. ${ }^{8} \mathrm{~A}$ recently published report of a European and North American task force on measurement of HRV for clinical use indicated sparse availability of information on the reliability of short segment recordings. ${ }^{11}$

We undertook two studies in an unselected free living population sample to determine the feasibility and potential usefulness of five minute recordings in men and women aged 35-65 years. Recordings were made under conditions of free and standardised breathing, the latter by metronomic controlled breathing at a rate of 15 breaths per minute to accentuate the predominantly parasympathetically determined high frequency response. ${ }^{3}{ }^{12} \mathrm{HRV}$ can be measured in terms of the time domain or frequency domain. ${ }^{12-14}$ We report on the within individual repeatability of supine HRV measures over several months, as well as sex and age associations of HRV measures under field conditions in a population of kibbutz residents in Israel.

\section{Subjects and methods}

STUDY DESIGN AND DATA COLLECTION

Our data derive from two separate studies, one aimed to appraise repeatability of HRV with time, and the second to assess the association of HRV, determined from short recordings, with age and sex. To establish repeatability of these measures, we undertook a study in a sample of 70 members from a single kibbutz. This sample comprised 32 men and 38 women who were measured twice (between 15:00 and 19:00) with a two month interval. Measurements were performed over a six to seven month interval in an additional eight participants. The first HRV measurement was performed after a 12 lead ECG, so that participants were in a supine position for at least 20 minutes before beginning Holter recording, whereas during the second HRV measurement the supine resting period was about 10 minutes.

The second section of our study, the objective of which was to investigate the population characteristics of $\mathrm{HRV}$, followed an 
evaluation of coronary heart disease risk factors undertaken in 10 communal kibbutz settlements, five religious and five secular, in northern Israel. A representative sample of nearly 600 free living men and women aged 35-65, equally divided between the sexes and three 10 year age groups, was invited to participate. The overall response rate was $79 \%$ $(n=465)$. A random sample of participants in the first stage comprising 348 men and women was reinvited approximately one year later to participate in HRV measurements not performed at the initial stage. This sample generated five or six men and five or six women from each of the three age bands in all 10 kibbutzim. Examination was performed between 06:30 and $12: 30$ and included a 12 lead resting ECG followed by HRV measurement by Holter recording, so that participants were in a supine position for at least 20 minutes before beginning Holter recording. The response rate at this second visit was $86 \%$ (five people were subsequently excluded from these analyses because of technical problems).

The study was approved by the appropriate institutional review board and all participants provided signed informed consent.

HOLTER RECORDING AND ANALYSES

Holter recording was carried out using a Marquette 8500 recorder after a resting period in the supine position. The recordings were undertaken in each kibbutz in a quiet room under standardised conditions. Participants were instructed to avoid a heavy meal, abstain from smoking, caffeine containing beverages, and alcohol, and to avoid demanding physical activity for at least two hours before measurement. After connection of the chest leads the recordings were performed during approximately six minutes of silent supine free breathing and then approximately six minutes of supine metronomic controlled breathing at 15 breaths per minute, which clearly distinguishes and accentuates the high frequency vagal component. ${ }^{3} 121516$

Holter cassette tapes were analysed on a Marquette series 8000 analysis system using two channels: a modified V5 lead and a modified V1 lead. Files with RR intervals and their annotations (normal beats, extrasystoles, and artefacts) were transferred to a 486 personal computer through an RS-232 serial port using the XMODEM protocol. RR intervals were calculated using a computer program and editing routines developed by Sapoznikov et al. ${ }^{17}$ This method, based on the absolute differences between heart rate (HR) values and both the last normal $H R$ value and an updated mean, is used for removal of artefacts and arrhythmias. Five minute epochs of $\mathrm{HR}$ as a function of time were used for time domain (ms) and power spectrum (PS) analysis $\left(\mathrm{ms}^{2}\right)$. PS analysis (without a detrending algorithm) was performed with a 16th order autoregressive model and solving the Yule-Walker equations by the Levinson algorithm. ${ }^{18}$ Three frequency bands were analysed: 0.0033 to $<0.04 \mathrm{~Hz}$ (very low), 0.04 to $<0.15 \mathrm{~Hz}$ (low), and 0.15 to $0.40 \mathrm{~Hz}$ (high).
In short recordings of HRV, as in this study, the ultra low frequency (ULF) is not computed and the very low frequency (VLF), although computed, is presumably not stably estimated by a five minute record. ${ }^{11}$

Frequency domain variables included the area of each of the three main frequency bands, the area of the total power between $0.0033 \mathrm{~Hz}$ and $0.40 \mathrm{~Hz}$ (total PS), and the ratio of low to high frequencies, the latter considered by some as a measure reflecting sympathetic/parasympathetic balance, ${ }^{4}$ but this interpretation is strongly disputed by others. ${ }^{19}$ Two time domain measures, the standard deviation (SD) of RR intervals, which represents total variability, and the root mean square of successive differences in RR intervals (RMSSD), which represents the beat to beat variability, were also considered.

A second technician re-read 32 recordings to assess technician variability in the editing routine. The repeat readings also take into account the artefact elimination routine, the effect of which was not formally assessed alone, but rather as part of the whole process of editing. The repeated readings were highly correlated for all HRV indices in both breathing conditions (Pearson correlations between 0.96 and 0.99 ) and hence the editing process is largely invariable between technicians. This finding is similar to that reported by the atherosclerosis risk in communities study. ${ }^{20}$

\section{DATA ANALYSIS}

As all HRV indexes were skewed, a natural logarithmic transformation was used to normalise the data adequately. The reliability analysis was undertaken on $\ln$ transformed data, using a nested analysis of variance with random effects, implemented by SAS PROC NESTED. ${ }^{21}$ We then calculated the reliability coefficient $(\mathrm{R})$, which is the proportion of total variance attributed to the between person component (and is equivalent to the Pearson correlation coefficient when only two repeated measures are considered), and the conventional coefficient of variation. ${ }^{22}$ Linear regression was used to assess the association between age and HRV under different breathing conditions also controlling for HR (which has been shown to affect HRV). ${ }^{15}$ These analyses were done for each sex separately (not shown) and for the combined sex adjusted data.

The data were adjusted for the effect of age and HR to assess differences between the sexes in HRV indices. Values of HRV measures were regressed within each sex on the independent variables: age and $\mathrm{age}^{2}$ in one analysis (controlled for age), and HR was added to the regression equation in a second analysis (controlled for age and HR). HR was inversely associated in both sexes with all HRV indices, correlations ranging between -0.33 and -0.59 in men and -0.24 and -0.44 in women.

Dependency of the sample variances on age or age and HR was examined for heteroscedasticity by regressing the squared residual $\left(\mathrm{r}^{2}\right)$ from previous regressions on age and HR using the same models. No significant heteroscedasticity emerged. 
Table 1 Characteristics of the study populations

\begin{tabular}{lll}
\hline & Men & Women \\
\hline Single kibbutz in which repeated measures were made & $\mathrm{n}=32$ & $\mathrm{n}=38$ \\
Age (years) & $48.9(6.8)$ & $48.5(7.2)$ \\
Heart rate (beats/min) & $69.2(6.7)$ & $69.2(9.6)$ \\
Body mass index $\left(\mathrm{kg} / \mathrm{m}^{2}\right)$ & $26.1(3.0)$ & $25.5(3.4)$ \\
Total cholesterol $(\mathrm{mg} / \mathrm{dl})$ & $199(35)$ & $203(33)$ \\
LDL cholesterol $(\mathrm{mg} / \mathrm{dl})$ & $132(31)$ & $129(31)$ \\
HDL cholesterol $(\mathrm{mg} / \mathrm{dl})$ & $38(8)$ & $51(11)$ \\
Triglycerides $(\mathrm{mg} / \mathrm{dl})$ & $156(100)$ & $117(54)$ \\
Sample drawn from 10 kibbutzim in cross sectional study & $\mathrm{n}=147$ & $\mathrm{n}=147$ \\
Age (years) & $51.6(8.0)$ & $50.9(8.4)$ \\
Heart rate (beats/min) & $64.1(10.1)$ & $67.5(7.8)$ \\
Systolic blood pressure (mm Hg) & $126(16)$ & $119(16)$ \\
Diastolic blood pressure (mm Hg) & $81(10)$ & $75(9)$ \\
Body mass index $\left(\mathrm{kg} / \mathrm{m}^{2}\right)$ & $27.0(3.9)$ & $25.9(4.5)$ \\
Total cholesterol (mg/dl) & $202(36)$ & $203(39)$ \\
LDL cholesterol $(\mathrm{mg} / \mathrm{dl})$ & $134(32)$ & $129(33)$ \\
HDL cholesterol $(\mathrm{mg} / \mathrm{dl})$ & $41(9)$ & $52(11)$ \\
Triglycerides (mg/dl) & $141(81)$ & $115(63)$ \\
\hline
\end{tabular}

Values are mean (SD).

Plasma lipids and lipoproteins were measured after a 12 hour fast.

Heart rate was measured after lying supine in a quiet room for at least 20 minutes.

LDL, low density lipoprotein; HDL, high density lipoprotein.

\section{Results}

CHARACTERISTICS OF THE STUDY POPULATIONS

The mean age of the sample with repeated measures was 49 years (range $31-67$ ), whereas that of the 10 kibbutzim was 51 (range 35-65). Body mass index, blood pressure, and plasma lipids and lipoproteins (table 1) are similar to those of the Israeli population. The relatively low high density lipoprotein cholesterol concentration, particularly in men, is characteristic of the Jewish population of Israel.

\section{STABILITY OF HRV MEASURES WITH TIME}

Reliability was appraised in 70 individuals over a two month period (table 2). The lowest reliability coefficient is seen for the very low frequency area (0.65 with free breathing and 0.64 with metronomic breathing). All other $\mathrm{HRV}$ indices had reliability coefficients of 0.68 to 0.77 under free breathing and 0.75 to 0.82 under metronomic breathing. Reliability tended to be higher among women than men but this difference was not significant and was similar in younger and older patients. Reliability when expressed as the within person coefficient of variation (consisting of biological variation and method error) ranged between
$6.0 \%$ and $12.1 \%$ for free breathing and between $6.1 \%$ and $10.7 \%$ for metronomic breathing for HRV indices. Overall, these analyses indicate considerable temporal stability over a short time span under field conditions. For most measures HRV using the metronome showed similar consistency with time than under free breathing conditions. Even the very low frequency band which should be interpreted with caution in short recordings (five minutes or less) ${ }^{11}$ showed reasonable repeatability and hence reasonable information even in five minute recordings.

Spearman's correlation coefficients in the eight participants in whom we assessed reliability of HRV measures over a six to seven month interval were between 0.85 and 0.98 under free breathing, indicating considerable consistency over a longer period (detailed data not shown).

\section{CONSTRUCT VALIDITY OF HRV MEASURES}

Sex differences

Men breathing spontaneously had significantly higher age adjusted total variability than women (table 3). This difference in total PS resulted from higher power in the very low and low frequency bands among men, whereas the high frequency component was similar in both sexes. Thus, the ratio of low frequency to the high frequency power was considerably higher among men. A similar relation with sex was seen with the time domain measure, RMSSD, which is highly correlated with the high frequency component $(r \geqslant 0.95)$ and for the $\mathrm{SD}$, which is highly correlated with total PS $(r \geqslant 0.97)$. The difference between the sexes in the high frequency band and the RMSSD became significant with adjustment for age and HR, women having higher values than men. When HR was held constant, the proportion of total variability in the high frequency range was greater in women than men, whereas men had greater very low and low frequency power; this resulted in similar total variability in both sexes, as evidenced by the small sex differences in SD and total PS

Under metronomic controlled breathing (adjusted for age), men showed higher power in

Table 2 Mean values, coefficients of variations, and correlation coefficients of ln transformed heart rate variation indices in 70 kibbutz members recorded two months apart

\begin{tabular}{|c|c|c|c|c|c|c|c|c|c|c|}
\hline & & \multirow{2}{*}{$\begin{array}{l}\text { Sample } \\
\text { mean } \\
(n=70)\end{array}$} & \multirow{2}{*}{$\begin{array}{l}\text { Coefficient of } \\
\text { variation }(\%) \\
(n=70)\end{array}$} & \multirow{2}{*}{$\begin{array}{l}\text { Correlation } \\
\text { coefficient } \\
(n=70)\end{array}$} & \multicolumn{3}{|c|}{ Correlation } & \multicolumn{3}{|l|}{ Correlation } \\
\hline & & & & & $\begin{array}{l}\text { Men } \\
(n=32)\end{array}$ & $\begin{array}{l}\text { Women } \\
(n=38)\end{array}$ & $p$ & $\begin{array}{l}\text { Age }<50 \\
(n=45)\end{array}$ & $\begin{array}{l}\text { Age } \geqslant 50 \\
(n=25)\end{array}$ & $p$ \\
\hline \multirow[t]{2}{*}{ SD } & Free & 3.63 & 6.0 & 0.77 & 0.71 & 0.83 & NS & 0.79 & 0.74 & NS \\
\hline & Metronome & 3.59 & 6.1 & 0.78 & 0.66 & 0.84 & NS & 0.75 & 0.78 & NS \\
\hline \multirow[t]{2}{*}{ RMSSD } & Free & 3.29 & 8.0 & 0.75 & 0.66 & 0.79 & NS & 0.83 & 0.62 & NS \\
\hline & Metronome & 3.29 & 7.4 & 0.78 & 0.59 & 0.86 & $<0.05$ & 0.81 & 0.73 & NS \\
\hline \multirow[t]{2}{*}{ Area very low } & Free & 5.45 & 9.0 & 0.65 & 0.56 & 0.73 & NS & 0.70 & 0.60 & NS \\
\hline & Metronome & 5.27 & 9.7 & 0.64 & 0.61 & 0.68 & NS & 0.63 & 0.66 & NS \\
\hline \multirow[t]{2}{*}{ Area low } & Free & 5.30 & 11.5 & 0.68 & 0.69 & 0.70 & NS & 0.62 & 0.70 & NS \\
\hline & Metronome & 4.95 & 10.7 & 0.75 & 0.77 & 0.72 & NS & 0.66 & 0.79 & NS \\
\hline \multirow[t]{2}{*}{ Area high } & Free & 4.95 & 12.1 & 0.76 & 0.74 & 0.78 & NS & 0.80 & 0.69 & NS \\
\hline & Metronome & 5.11 & 10.5 & 0.82 & 0.72 & 0.87 & NS & 0.84 & 0.80 & NS \\
\hline \multirow{2}{*}{ Total PS } & Free & 6.45 & 7.0 & 0.77 & 0.71 & 0.83 & NS & 0.78 & 0.74 & NS \\
\hline & Metronome & 6.33 & 6.7 & 0.80 & 0.72 & 0.84 & NS & 0.77 & 0.82 & NS \\
\hline
\end{tabular}

SD, standard deviation of RR interval; RMSSD, root mean square of differences of successive RRs; area very low, the area at very low frequency $(0.0033$ to $<0.04$ $\mathrm{Hz})$; area low, the area at low frequency $(0.04$ to $<0.15 \mathrm{~Hz})$; area high, the area at high frequency $(0.15$ to $<0.40 \mathrm{~Hz})$; total PS, total power spectrum $(0.0033$ to $<$ $0.40 \mathrm{~Hz})$.

The values for the SD and RMSSD are in $\mathrm{ms}$ and the values for the areas and total power are in $\mathrm{ms}^{2}$.

Correlation coefficient measured as between subject variability expressed as percentage of total variability.

69 cases were included for metronomic breathing. 
Table 3 Sex differences in heart rate variability measures (In transformed) in supine position

\begin{tabular}{|c|c|c|c|c|c|c|}
\hline \multirow[b]{2}{*}{ Measures } & \multicolumn{3}{|l|}{ Controlled for age } & \multicolumn{3}{|c|}{ Controlled for age and heart rate } \\
\hline & Men mean $(S D)$ & Women mean $(S D)$ & $p$ & Men mean (SD) & Women mean (SD) & $p$ \\
\hline \multicolumn{7}{|l|}{ Free breathing } \\
\hline SD & $3.71(0.49)$ & $3.57(0.34)$ & 0.007 & $3.70(0.40)$ & $3.65(0.29)$ & 0.191 \\
\hline RMSSD & $3.26(0.49)$ & $3.26(0.42)$ & 0.916 & $3.25(0.36)$ & $3.38(0.34)$ & 0.003 \\
\hline Area very low & $5.80(0.98)$ & $5.44(0.72)$ & 0.001 & $5.78(0.83)$ & $5.59(0.65)$ & 0.029 \\
\hline Area low & $5.40(1.13)$ & $5.02(0.78)$ & 0.001 & $5.40(0.96)$ & $5.14(0.73)$ & 0.010 \\
\hline Area high & $4.84(1.12)$ & $4.85(0.93)$ & 0.920 & $4.83(0.86)$ & $5.09(0.77)$ & 0.008 \\
\hline Total PS & $6.61(0.98)$ & $6.33(0.68)$ & 0.005 & $6.61(0.78)$ & $6.49(0.58)$ & 0.156 \\
\hline Ratio (low to high) & $5.19(0.77)$ & $4.78(0.79)$ & $<0.001$ & $5.18(0.76)$ & $4.65(0.74)$ & $<0.001$ \\
\hline \multicolumn{7}{|l|}{ Metronomic breathing } \\
\hline SD & $3.60(0.44)$ & $3.55(0.34)$ & 0.290 & $3.59(0.38)$ & $3.61(0.31)$ & 0.631 \\
\hline RMSSD & $3.22(0.47)$ & $3.26(0.45)$ & 0.477 & $3.20(0.37)$ & $3.36(0.37)$ & $<0.001$ \\
\hline Area very low & $5.47(0.96)$ & $5.29(0.73)$ & 0.040 & $5.48(0.86)$ & $5.37(0.71)$ & 0.243 \\
\hline Area low & $4.98(1.00)$ & $4.66(0.80)$ & 0.003 & $4.96(0.91)$ & $4.76(0.77)$ & 0.047 \\
\hline Area high & $4.77(1.09)$ & $4.97(1.01)$ & 0.103 & $4.74(0.90)$ & $5.20(0.87)$ & $<0.001$ \\
\hline Total PS & $6.35(0.88)$ & $6.24(0.69)$ & 0.240 & $6.32(0.74)$ & $6.37(0.62)$ & 0.546 \\
\hline Ratio (low to high) & $4.81(0.80)$ & $4.30(0.90)$ & $<0.001$ & $4.82(0.78)$ & $4.18(0.84)$ & $<0.001$ \\
\hline
\end{tabular}

$\mathrm{SD}$, standard deviation of RR interval; RMSSD, root mean square of differences of successive RRs; area very low, the area at very low frequency $(0.0033$ to $<0.04 \mathrm{~Hz})$; area low, the area at low frequency $(0.04$ to $<0.15 \mathrm{~Hz})$; area high, the area at high frequency $(0.15$ to $<0.40 \mathrm{~Hz})$; total PS, total power spectrum $(0.0033$ to $<0.40 \mathrm{~Hz})$; ratio low to high, ratio of low frequency to high frequency. The values for the SD and RMSSD are in $\mathrm{ms}$ and the values for the areas and total power are in $\mathrm{ms}^{2}$.

$\mathrm{p}$ values from $t$ test for differences in means.

the very low and low frequency bands, whereas the high frequency band and the RMSSD were similar in both sexes, and the ratio of the low frequency to high frequency remained much higher among men. Total variability, which is represented as total PS in the frequency domain and as SD in the time domain, however, no longer differed significantly between men and women. Two main changes occur after adjustment for age and HR: the RMSSD and high power component became significantly higher among women, whereas the sex difference in very low and low frequency power, seen when only age adjusted, was reduced. The differences between men and women in the ratio of low to high frequency increased after controlling for HR, men maintaining a much higher ratio than women $(\mathrm{p}<0.001)$.
Association with age

There was a significant decline with age, for the combined sex adjusted data, for all HRV measures in both breathing conditions (table 4). This reduction in HRV with age was not altered significantly while controlling for HR. The ratio of low to high frequency power increased significantly with age in participants when free breathing but did not alter significantly with age when breathing was controlled.

The trend with age in HRV seemed to differ according to sex (data not shown): decline was evident only between the $45-54$ to 55-65 year age groups in women, while there was a graded decrease across the three age groups in men. A formal test of this interaction of age and sex on HRV (both in the unadjusted data and controlling for HR) in regression models, however, did not reach significance.

Table 4 Age differences in heart rate variabilty measures (In transformed, adjusted for sex) in supine position

\begin{tabular}{|c|c|c|c|c|c|c|c|c|c|c|c|c|c|c|}
\hline & \multicolumn{2}{|l|}{$S D$} & \multicolumn{2}{|c|}{$R M S D D$} & \multicolumn{2}{|c|}{ Area very low } & \multicolumn{2}{|c|}{ Area low } & \multicolumn{2}{|c|}{ Area high } & \multicolumn{2}{|c|}{ Total PS } & \multicolumn{2}{|c|}{ Ratio low:high } \\
\hline & $\overline{\text { Mean }}$ & Median & $\overline{M e a}$ & Median & $\overline{M e a n}$ & Median & $\overline{M e a}$ & Median & $\overline{\text { Mean }}$ & Median & $\overline{\text { Mean }}$ & Median & $\overline{M e a n}$ & Median \\
\hline \multicolumn{15}{|l|}{ Free breathing } \\
\hline $35-44$ years $(\mathrm{n}=91)$ & \multirow{2}{*}{\multicolumn{2}{|c|}{$(3.62-4.22)$}} & 3.48 & 3.49 & 6.11 & 6.03 & \multirow{2}{*}{\multicolumn{2}{|c|}{$(5.07-6.53)$}} & \multirow{2}{*}{\multicolumn{2}{|c|}{$(4.62-5.93)$}} & \multirow{2}{*}{\multicolumn{2}{|c|}{$(6.47-7.67)$}} & 5.13 & 5.06 \\
\hline $25-75$ percentile & & & \multicolumn{2}{|c|}{$(3.14-3.80)$} & \multicolumn{2}{|c|}{$(5.52-6.63)$} & & & & & & & \multicolumn{2}{|c|}{$(4.54-5.65)$} \\
\hline $45-54$ years $(n=108)$ & 3.60 & 3.65 & 3.17 & 3.20 & 5.60 & 5.63 & 5.18 & 5.21 & 4.69 & 4.70 & 6.40 & 6.47 & 5.09 & 5.12 \\
\hline $25-75$ percentile & \multicolumn{2}{|c|}{$(3.32-3.87)$} & \multicolumn{2}{|c|}{$(2.80-3.45)$} & \multicolumn{2}{|c|}{$(5.10-6.18)$} & \multicolumn{2}{|c|}{$(4.54-6.01)$} & \multicolumn{2}{|c|}{$(3.96-5.31)$} & \multicolumn{2}{|c|}{$(5.83-7.03)$} & \multicolumn{2}{|c|}{$(4.55-5.70)$} \\
\hline $55-65$ years $(n=94)$ & 3.61 & 3.58 & 3.10 & 3.08 & 5.70 & 5.64 & 5.16 & 5.13 & 4.42 & 4.47 & 6.41 & 6.38 & 5.34 & 5.33 \\
\hline $25-75$ percentile & \multicolumn{2}{|c|}{$(3.23-4.06)$} & \multicolumn{2}{|c|}{$(2.69-3.46)$} & \multicolumn{2}{|c|}{$(5.09-6.37)$} & \multicolumn{2}{|c|}{$(4.29-6.18)$} & \multicolumn{2}{|c|}{$(3.62-5.23)$} & \multicolumn{2}{|c|}{$(5.66-7.30)$} & \multicolumn{2}{|c|}{$(4.98-5.85)$} \\
\hline $\mathrm{p}$ value & \multicolumn{2}{|c|}{0.009} & \multicolumn{2}{|c|}{0.004} & \multirow{2}{*}{\multicolumn{2}{|c|}{$\begin{array}{l}0.003 \\
0.0005\end{array}$}} & $<0$ & & 0.009 & & 0.014 & & 0.03 & \\
\hline $\mathrm{p}$ value (controlled for $\mathrm{HR}$ ) & 0.01 & & 0.00 & & 0.000 & & $<0$ & & 0.010 & & 0.02 & & 0.03 & \\
\hline Metronomic breathing & & & & & & & & & & & & & & \\
\hline $35-44$ years $(n=91)$ & 3.76 & 3.81 & 3.41 & 3.46 & 5.70 & 5.71 & 5.39 & 5.39 & 5.19 & 5.31 & 6.67 & 6.70 & 4.81 & 4.81 \\
\hline $25-75$ percentile & $(3.52$ & $.99)$ & (3.1 & $.71)$ & $(4.99$ & $.33)$ & $(4.7$ & $.02)$ & $(4.43$ & $5.78)$ & $(6.19$ & $.07)$ & $(4.27-5$ & $.43)$ \\
\hline $45-54$ years $(n=107)$ & 3.54 & 3.51 & 3.16 & 3.16 & 5.40 & 5.27 & 4.88 & 4.96 & 4.66 & 4.66 & 6.24 & 6.19 & 4.83 & 4.79 \\
\hline $25-75$ percentile & $(3.25$ & $.79)$ & $(2.8$ & $47)$ & $(4.73$ & $.90)$ & $(4.2$ & $60)$ & $(4.03$ & $.31)$ & $(5.70$ & 5.83) & $(4.32-5$ & $.48)$ \\
\hline $55-65$ years $(n=93)$ & 3.48 & 3.45 & 3.05 & 3.03 & 5.36 & 5.33 & 4.60 & 4.59 & 4.41 & 4.36 & 6.09 & 6.01 & 4.79 & 4.85 \\
\hline $25-75$ percentile & $(3.15$ & $.81)$ & $(2.7$ & .40) & $(4.76$ & $.92)$ & $(3.92$ & $37)$ & $(3.58$ & $5.22)$ & $(5.54$ & 5.78) & $(4.40-5$ & $.28)$ \\
\hline $\mathrm{p}$ value & $<0.0$ & & 0.00 & & 0.000 & & $<0$. & & 0.011 & & $<0.0$ & & NS & \\
\hline $\mathrm{p}$ value (controlled for HR) & $<0.0$ & & 0.00 & & 0.000 & & $<0$ & & 0.014 & & $<0.0$ & & NS & \\
\hline
\end{tabular}

SD, standard deviation of RR interval; RMSSD, root mean square of differences of successive RRs; area very low, the area at very low frequency $(0.0033$ to $<0.04$ $\mathrm{Hz})$; area low the area at low frequency $(0.04$ to $<0.15 \mathrm{~Hz})$; area high, the area at high frequency $(0.15$ to $<0.40 \mathrm{~Hz})$; total PS, total power spectrum $(0.0033$ to $<$ $0.40 \mathrm{~Hz})$; ratio low to high, ratio of low frequency to high frequency.

The values for the SD and RMSSD are in ms and the values for the areas and total power are in $\mathrm{ms}^{2}$.

$\mathrm{p}$ value is from a linear regression of heart rate variability on age.

$\mathrm{p}$ value (controlled for heart rate) is from a linear regression of HRV on age and HR. 


\section{Discussion}

RELIABILITY

The HRV measures recorded by Holter in the supine position for five minute periods are stable. The high reliability coefficient and the low coefficient of variation (which includes biological variability and method error) of these short recordings indicate a considerable consistency with time. Our results, based on a small sample of eight participants over a six to seven month interval and the sample of 70 participants measured twice with a two month interval, are in agreement with those of small studies of healthy individuals ${ }^{12324}$ and show that HRV indices remain stable over several months and may be regarded as characterising the individual. This finding substantiates the usefulness of short HRV recordings. The coefficient of variation can be minimised by adherence to the study protocol under field conditions to maintain small variation. The manual editing routine was very reliable and contributed little to measurement error.

SPONTANEOUS VERSUS METRONOMIC BREATHING In our study the measures were undertaken in two breathing conditions. The advantage of using metronomic controlled breathing is the ability to distinguish and accentuate vagal activity as manifested in the high frequency component. High frequency power, which is respiratory dependent, is maximised in a peak at the hertz equivalent of the respiratory rate. At 15 respirations per minute the high frequency peak appears in a constant position in all individuals (at $0.25 \mathrm{~Hz}$ ) and is completely separated from the low frequency peak, whereas under spontaneous breathing the position of the high frequency band and its shape depend on the breathing rate. The high frequency peak of individuals who breath less than nine times per minute would be misclassified as low frequency using the cut off points here $(0.15 \mathrm{~Hz})$. Misclassification ${ }^{25}$ is not unusual in a study of healthy individuals in the supine position, and metronomic controlled breathing serves as a convenient and simple way of avoiding this problem. In practice, however, the effect of the metronome on temporal stability of the HRV measures was small. This manoeuvre is not required to obtain reliable measures of high frequency power in a healthy population using short duration recordings.

TIME VERSUS FREQUENCY DOMAIN MEASURES Frequency domain measures provide information of different quality and detail from that expressed by time domain analysis. However, agreement is extremely high for measures comparable between the two modes of appraising HRV (namely SD $v$ total power and RMSSD $v$ high frequency power). This finding suggests that simpler time domain analyses may be appropriate for some uses.

HR AND ITS ASSOCIATION WITH HRV INDICES Our findings of strong associations between $\mathrm{HR}$ and $\mathrm{HRV}$ indices are consistent with those of other studies. Nevertheless, the common practice of adjusting $\mathrm{HRV}$ indices for $\mathrm{HR}^{1523}$ requires thought and may lead to over adjustment. ${ }^{23}$ Sex differences in high frequency power, total power, and the ratio of low to high power were altered on adjustment for HR, which is itself under autonomic control.

\section{Age associations}

Our findings of the effect of age concord with those of several studies in healthy adults. ${ }^{26-32}$ Our study and two additional studies ${ }^{26}{ }^{32}$ were based on population samples. Several studies relied on a relatively small sample size and a broad age range 7-29 $31^{27}$ and some used different measures making comparison difficult. ${ }^{30} \mathrm{~Pa}-$ gani et al reported that the ratio of low to high frequency does not change with age. ${ }^{4}$ Our findings show that the low to high frequency power ratio is unchanged with age only under metronomic breathing. Our data show that although the decline with age occurs in both sexes, it may begin earlier in men. These alterations with age should be considered when evaluating HRV in study populations of different age structure.

\section{Sex differences}

We have shown clearly in this study population, representative of Jewish men and women living in 10 kibbutzim in Israel, that HRV measures differ considerably between the sexes. Sex differences under free breathing in RMSSD and the high frequency component (not adjusted for $\mathrm{HR}$ ), measures reflecting predominantly vagal activity, were small and not significant. However, the ratio of low to high frequencies, which has been considered by some investigators as a measure of sympathetic/parasympathetic balance, ${ }^{42}$ differed substantially. This resulted from greater very low and low frequency power in men, which may reflect relatively higher sympathetic activity in men than in women. This common interpretation has been vigorously contested. ${ }^{19}$

Our findings from five minute recordings, which indicate that women have lower total variability (free breathing only), lower low frequency power, but equal or even higher high frequency power are consonant with observations in other studies. ${ }^{26}{ }^{31-33}$ Some inconsistency among studies may also result partly from differences in analytical methods, including control or lack of control for both age and HR.

The results of the atherosclerosis risk in communities study, which used two minute ECG recordings in a very large population and applied fast Fourier transformation (which may be less preferable for short time segments), ${ }^{18}{ }^{34}$ are generally consistent with our findings. ${ }^{32}$ Van Hoogenhuyze et al assert that sex differences are exclusively due to HR differences. ${ }^{23}$ Our findings do not concur with this conclusion. In a small population based sample, Kupari et al reported clear sex differences on adjustment for $\mathrm{HR}^{15}$ as seen in our study but suggested that this finding occurred because of the confounding effect of low density lipoprotein (LDL) cholesterol, which was inversely related to HRV. We consider justification for such control for LDL cholesterol to be questionable. 
Our findings of a relatively greater high frequency component of total variability in women aged between 35 and 65 may relate to the overall protection of women against coronary heart disease, and in particular coronary mortality and sudden cardiac death, compared with that for men, and the loss of protection in postmenopausal women. HRV in postmenopausal women given hormone replacement therapy may be higher than in women who do not receive such treatment, ${ }^{33}$ suggesting that hormonal factors may have favourable effects on cardiovascular autonomic regulation and may partly explain the sex differences. This also suggests a mechanism for the protective effects of hormone replacement reported in observational studies.

A possible protective mechanism could relate to enhanced vagal activity putatively expressed by greater high frequency relative to low frequency power, being associated with a reduced susceptibility to dysrhythmia. However, Bigger $e t a l,{ }^{35}$ in their study of men after an acute MI, support a protective role for overall HRV with no clear predilection for specific frequency bands or specific coronary heart disease outcomes. Furthermore, the low frequency component was the most strongly associated with four year total mortality in an elderly Framingham cohort. ${ }^{10}$ The implications of sex and age differences reflected by high frequency variation or the ratio of low to high frequencies therefore remain unclear.

\section{CONCLUSIONS}

HRV measures represent a non-invasive reflection of autonomic function. Short segment measures are simple to perform and suitable for epidemiological field studies. A limitation may result from inability to measure ULF (frequency $<0.0033 \mathrm{~Hz}$ ) and the measurement of VLF (between 0.0033 and $0.04 \mathrm{~Hz}$ ) may be less reliable.

Our data show that: (1) HRV measures derived from five minute recordings are stable and may be regarded as characteristic of an individual; VLF may by less repeatable than the LF and HF but even VLF was associated with reasonable stability; (2) there are clear differences between the sexes; and (3) HRV declines with age in both sexes. These data, in addition to accumulating knowledge about the association of HRV with risk factors for coronary heart disease, ${ }^{15}$ mortality after an acute $\mathrm{MI},{ }^{568}$ the incidence of coronary heart disease, ${ }^{9}$ and total mortality, ${ }^{10}$ point towards the value of incorporating short segment HRV measures into population studies.

The authors acknowledge the contribution of the late Dr Shusterman in data collection. This study was supported by the German-Israel Foundation for Scientific Research and Development.

1 Kleiger RE, Bigger JT, Bosner MS, et al. Stability over time , jects. Am f Cardiol 1991;68:626-30.

2 Akselrod S, Gordon D, Ubel FA, et al. Power spectrum analysis of heart rate fluctuation: a quantitative probe of beat to beat cardiovascular control. Science 1981;213:2203 .

Pomeranz B, Macaulay RJB, Caudill MA, et al. Assessment of autonomic function in humans by heart rate spectral analysis. Am F Physiol 1985;248:H151-3.
4 Pagani M, Lombardi F, Guzzetti S, et al. Power spectral analysis of heart rate and arterial pressure variabilities as a marker of sympathovagal interaction in man and conscious dog. Circ Res 1986;59:178-93.

5 Kleiger RE, Miller JP, Bigger JT, et al, and the Multicenter Post-infarction Research Group. Decreased heart rate variability and its association with increased mortality after acute myocardial infarction. Am f Cardiol 1987;59:256-62.

6 Ewing DJ. Heart rate variability: an important new risk factor in patients following myocardial infarction. Clin Cardiol 1991;14:683-5.

7 Casolo GC, Stroder P, Signorini C, et al. Heart rate variability during the acute phase of myocardial infarction. Circulation 1992;85:2073-9.

8 Bigger JT, Fleiss JL, Rolnitzky LM, et al. The ability of several short-term measures of RR variability to predict mortality after myocardial infarction. Circulation 1993;88: mort-34.

9 Tsuji H, Larson MG, Venditti FJ, et al. Impact of reduced heart rate variability on risk for cardiac events: the Framingham heart study. Circulation 1996;94:2850-5.

10 Tsuji $\mathrm{H}$, Venditti FJ, Manders ES, et al. Reduced heart rate variability and mortality risk in an elderly cohort: the Framingham heart study. Circulation 1994;90:878-83.

11 Task Force of the European Society of Cardiology and the North American Society of Pacing and Electrophysiology. Heart rate variability: standards of measurement, physiological interpretation, and clinical use. Eur Heart f 1996; 17:354-81.

12 Hayano J, Sakakibara Y, Yamada A, et al. Accuracy of assessment of cardiac vagal tone by heart rate variability in normal subjects. Am f Cardiol 1991;67:199-204.

13 Ewing DJ, Borsey DQ, Bellavere F, et al. Cardiac autonomic neuropathy in diabetes: comparison of measures of R-R interval variation. Diabetologia 1981;21:18-24.

14 Bigger JT, Albrecht P, Steinman RC, et al. Comparison of time and frequency domain based measures of cardiac parasympathetic activity in Holter recordings after myocardial infarction. Am $\mathcal{F}$ Cardiol 1989;64:536-8.

15 Kupari M, Virolainen J, Koskinen P, et al. Short term heart rate variability and factors modifying the risk of coronary artery disease in a population sample. Am $\mathrm{f}$ Cardiol 1993;72:897-903.

16 Hayano J, Yamada A, Mukai S, et al. Severity of coronary atherosclerosis correlates with the respiratory componen of heart rate variability. Am Heart f 1991;121:1070-9.

17 Sapoznikov D, Luria MH, Mahler Y, et al. Computer processing of artifact and arrhythmias in heart rate variability analysis. Comput Methods Programs Biomed 1992;39:75-84

18 Marple SL. Digital spectral analysis. Englewood Cliffs: Prentice Hall, 1987.

19 Eckberg DL. Sympathovagal balance a critical appraisal. Circulation 1997;96:3224-32.

20 Liao D, Evans GW, Chambless LE, et al. Population based study of heart rate variability and prevalent myocardial infarction - the atherosclerosis risk in communities study. $\mathcal{F}$ Electrocardiol 1996;29:189-98.

21 SAS Institute. SAS/STAT user's guide, vol 1, version 6, 4th ed. Cary: SAS Institute, 1990

22 Chambless LE, McMahon RP, Brown SA, et al. Short term intraindividual variability in lipoprotein measurments: the atherosclerosis risk in communities (ARIC) study. $A m \mathcal{F}$ Epidemiol 1992;136:1069-81.

23 Van Hoogenhuyze D, Weinstein N, Martin GJ, et al. Reproducibility and relation to mean heart rate of heart rate variability in normal subjects and in patients with congestive heart failure secondary to coronary artery disease. Am 7 Cardiol 1991;68:1668-76.

24 Hohnloser SH, Klingenheben T, Zabel M, et al. Intraindividual reproducibility of heart rate variability. PACE 1992; 15:2211-14.

25 Sapoznikov D, Luria MH, Mahler Y, et al. Effects of the lower frequency limit on determining high frequency power of heart rate fluctuations. Proceedings IEEE Engineering in Medicine and Biology 1992;14:610-11.

26 Molgaard H, Hermansen K, Bjerregaard P. Spectral components of short term RR interval variability in healthy subjects and effects of risk factors. Eur Heart $\mathcal{F} 1994 ; 15$ : $1174-83$

27 Schwartz JB, Gibb WJ, Tran T. Aging effects on heart rate variation. F Gerontol A Biol Sci Med Sci 1991;46:M99-106.

28 Shannon DC, Carley DW, Benson H. Aging of modulation of heart rate. Am ₹ Physiol 1987;253:H874-7.

29 Lipsitz LA, Mietus J, Moody GB, et al. Spectral characteristics of heart rate variability before and during postural tilt: relations to aging and risk of syncope. Circulation 1990;81: 1803-10.

30 O'Brien IAD, O'Hare P, Corrall RJM. Heart rate variability in healthy subjects: effect of age and the derivation of normal ranges for tests of autonomic function. Br Heart $\mathcal{F}$ 1986;55:348-54

31 Sapoznikov D, Luria MH, Mahler Y, et al. Day vs night ECG and heart variability patterns in patients without obvious heart disease. F Electrocardiol 1992; 25:175-84.

32 Liao D, Barnes RW, Chambless LE, et al. Age, race and sex differences in autonomic cardiac function measured by spectral analysis of heart rate variability-the ARIC study. Am $\mathcal{F}$ Cardiol 1995;76:906-12

33 Huikuri HV, Pikkujamsa SM, Airaksinen KEJ, et al. Sex related differences in autonomic modulation of heart rate in middle aged subjects. Circulation 1996;94:122-5.

34 Cowan MJ, Burr RL, Narayanan SB, et al. Comparison of autoregression and fast Fourier transform techniques for power spectral analysis of heart period variability of 
persons with sudden cardiac arrest before and after therapy persons with sudden cardiac arrest before and after therapy to increase heart
35 Bigger JT, Fleiss JL, Steinman RC, et al. Frequency domain measures of heart period variability and mortality after myocardial infarction. Circulation 1992:85:164-71.

\section{IMAGES IN CARDIOLOGY}

\section{Congenital right pulmonary artery to left atrial fistula}

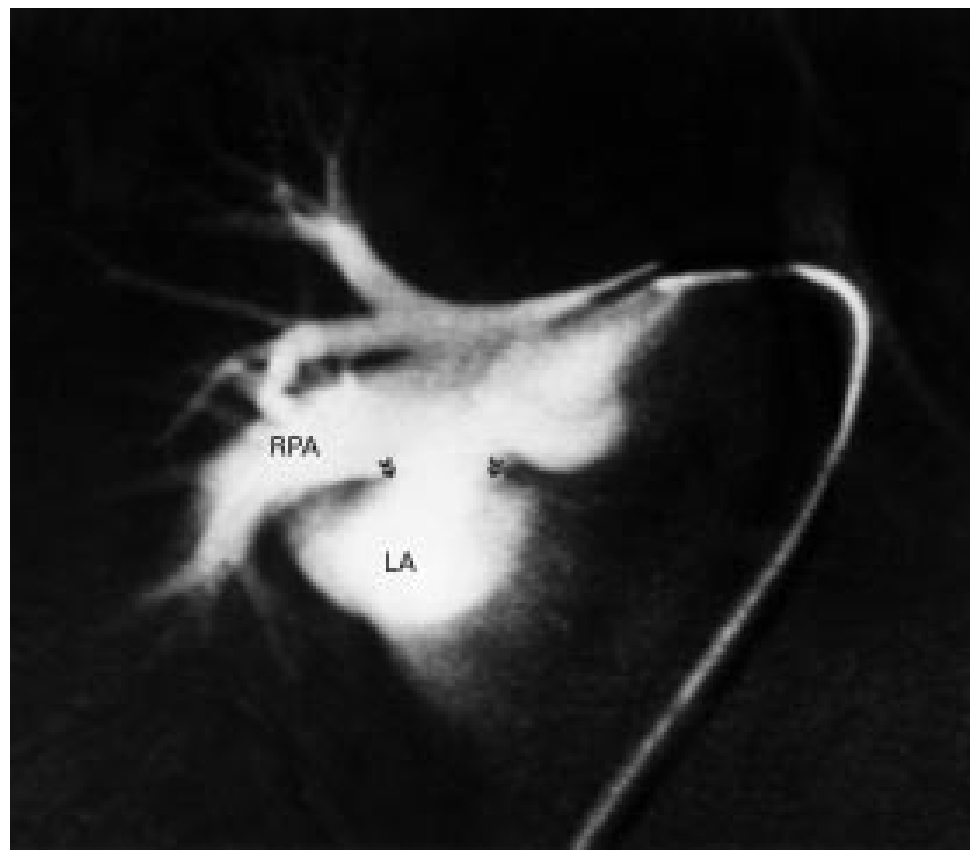

A 14 year old boy presented with a two year history of central cyanosis. His oxygen saturation in air was $77 \%$, but precordial echocardiography failed to detect any abnormality. Pulmonary angiography revealed a large direct communication (arrows) between the proximal right pulmonary artery (RPA) and the superior aspect of the left atrium (LA). The left pulmonary artery and the pulmonary venous return were normal, and there was no evidence of any other right to left shunting. Surgical repair of the defect is awaited.

Congenital right pulmonary to left atrial fistula usually involves the proximal right pulmonary artery or its lower lobe division. Although rare, it is an important cause of central cyanosis in the absence of other clinical findings.

G VELDTMAN

M E C BLACKBURN J PARSONS 